\title{
Hydrogenation of Isophthalonitrile with 1-Methylimidazole as an Effective Solvent for $\boldsymbol{m}$-Xylenediamine Production
}

\author{
Tae Young Chae, Sung Wook Row, Kye Sang Yoo, 'Sang Duek Lee, and Do Weon Lee ${ }^{\dagger}$ \\ Environment \& Process Technology Division, KIST, Seoul 136-791, Korea. *E-mail: kyoo@kist.re.kr \\ 'Department of Chemical Engineering, University of Seoul, Seoul 130-743, Korea \\ Received December 7, 2005
}

Key Words : $m$-Xylenediamine, 1-Methylimidazole, Hydrogenation, Effective solvent

meta-Xylenediamine (MXDA) is useful as chemical intermediates in the plastic and polymer fields. This compound can be prepared from the hydrogenation of isophthalonitrile (IPN) in the presence of ammonia using nickel catalyst or other metallic catalysts under high temperature and pressure. However, optimum reaction conditions are crucial to produce a high grade of MXDA because of the formation of undesirable products resulting from a partial hydrogenation, a polymerization or cleavage of the product. ${ }^{1}$ In order to prevent the side reactions, IPN were hydrogenated in the presence of ammonia with organic solvents. Especially, the correct choice of a solvent is a critical factor to govern the catalytic activity with desirable hydrogenation. ${ }^{2}$ Conventionally, organic materials such as aromatic hydrocarbons, aliphatic alcohols, aliphatic hydrocarbons, dimethylformamide and dioxane were employed in this reaction. Several MXDA producing processes with the organic solvent including $m$-xylene, pseudocumene, mesitylene, ethylben- zene, methylpyridine, benzonitrile, $m$-tolunitrile, MXDA and cyanopyridine were disclosed. ${ }^{3}$ However, the solvents and ammonia were vaporized under the operation conditions leading to amine cleavage with the resulting formation of methylbenzyl amines or the consumption of ammonia was still significant. Recently, some researchers reported that a high yield of MXDA was achieved using isopropanol under relatively low pressure condition; however, the consumption of ammonia was very significant. ${ }^{4}$

In this study, we used 1-methylimidazole for the hydrogenation of IPN to produce MXDA. Imidazole is a heterocyclic compound of five-membered diunsaturated ring structure composed of three carbon atoms and two nitrogen atoms at nonadjacent positions. Imidazoles are barely soluble in water normally, but are dissolved in organic solvents. ${ }^{5}$ Here we report the successful preparation of MXDA by hydrogenation of IPN in the presence of low ammonia concentration using 1-methylimidazole as an

Table 1. Hydrogenation of IPN with various reaction conditions

\begin{tabular}{|c|c|c|c|c|c|c|c|}
\hline Entry $^{a}$ & Solvent & $\begin{array}{l}\text { Temp. } \\
\left({ }^{\circ} \mathrm{C}\right)\end{array}$ & $\begin{array}{l}\text { Pressure } \\
\text { (psig) }\end{array}$ & $\begin{array}{l}\text { Solvent amount } \\
(\mathrm{mol})\end{array}$ & $\begin{array}{c}\mathrm{NH}_{3} \text { amount } \\
(\mathrm{mol})\end{array}$ & $\begin{array}{l}\text { Reaction time } \\
(\min )^{b}\end{array}$ & $\begin{array}{c}\text { MXDA yield } \\
(\%)\end{array}$ \\
\hline 1 & 1-Methylimidazole & 90 & 1000 & 0.5 & 10 & 90 & 87 \\
\hline 2 & 1-Methylimidazole & 110 & 1000 & 0.5 & 10 & 60 & 94 \\
\hline 3 & 1-Methylimidazole & 130 & 1000 & 0.5 & 10 & 30 & 98 \\
\hline 4 & 1-Methylimidazole & 150 & 1000 & 0.5 & 10 & 15 & 93 \\
\hline 5 & 1-Methylimidazole & 130 & 600 & 0.5 & 10 & 30 & 90 \\
\hline 6 & 1-Methylimidazole & 130 & 800 & 0.5 & 10 & 30 & 98 \\
\hline 7 & 1-Methylimidazole & 130 & 1000 & 0.5 & 0 & 90 & 40 \\
\hline 8 & 1-Methylimidazole & 130 & 1000 & 0.5 & 1.5 & 45 & 71 \\
\hline 9 & 1-Methylimidazole & 130 & 1000 & 0.5 & 4.5 & 30 & 88 \\
\hline 10 & 1-Methylimidazole & 130 & 1000 & 0.5 & 7.5 & 30 & 98 \\
\hline 11 & 1-Methylimidazole & 130 & 1000 & 0.25 & 10 & 30 & 98 \\
\hline 12 & 1-Methylimidazole & 130 & 1000 & 0.1 & 10 & 30 & 93 \\
\hline 13 & 1-Methylimidazole & 130 & 1000 & 0.05 & 10 & 60 & 20 \\
\hline 14 & Benzyl Ether & 130 & 1000 & 0.5 & 10 & 60 & 61 \\
\hline 15 & Mesitylene & 130 & 1000 & 0.5 & 10 & 60 & 78 \\
\hline 16 & Isopropanol & 130 & 1000 & 0.5 & 10 & 30 & 52 \\
\hline
\end{tabular}

${ }^{a}$ Conversion of IPN is $100 \%$ under all reaction conditions. ${ }^{b}$ Duration to reach $100 \%$ conversion of IPN. 
effective solvent.

The influence of reaction temperature on MXDA yield in hydrogenation of IPN was given in Table 1 (entry 1-4). MXDA yield is significantly affected by the reaction temperature. At low temperature range, the yield of MXDA was increased with reaction temperature and then a maximum yield was observed. At $130{ }^{\circ} \mathrm{C}$ of reaction temperature, more than $98 \%$ yield was obtained. With further increasing temperature, the MXDA yield was decreased. The result is attributed to the formation of side products at high temperature. Indeed, bulky molecules by polymerization were detected at $150{ }^{\circ} \mathrm{C}$.

The availability of hydrogen should affect the extent of catalytic activity of a hydrogenation reaction. Since the pressure was developed by hydrogen, the pressure in the system is directly proportional to the availability of hydrogen. The effect of reaction pressure on the hydrogenation of IPN is shown in Table 1 (entry 3, 5, 6). With increasing pressure from 600 to 800 psig, the MXDA yield increased rapidly. Under lower hydrogen concentration, a partial hydrogenation was appeared to prevent the formation of MXDA. 2-methylbenzly amine was main impurity at 600 psig. However, above $800 \mathrm{psig}$, the effect of pressure hardly appeared on the MXDA yield.

The availability of ammonia should affect the extent of MXDA yield in this hydrogen reaction because ammonia has been used to prevent the cleavage of the amine group, and moreover minimizes the formation of amine polymers. As shown in Table 1 (entry 3, 7-10), the high amount of MXDA was obtained in a high ammonia concentration. The yield of MXDA decreased with decrease of ammonia concentration. The result indicates that the excess of ammonia is requested to operate efficiently as the protecting agent. It should be noted that the amount of ammonia spent in this study was fairly lower than other processes. The amount of ammonia used in the work was only $7 \mathrm{~mol}$ per IPN, but higher amount of ammonia, from 10 to $200 \mathrm{~mol}$, was consumed under the other solvents. ${ }^{1,3,4}$

The effect of 1-methylimidazole concentration on INP hydrogenation has been studied at a constant temperature and a hydrogen pressure (entry 3, 11-13). As the 1-methylimidazole concentration changes from 0.05 to $0.1 \mathrm{~mol}$, the MXDA yield increased from $20 \%$ to $93 \%$. Thereafter, the MXDA yield was almost constant even at high 1-methylimidazole concentration. The result is directly related to the solubility of IPN to the 1-methylimidazole. Under lower amount of 1-methylimidazole condition, IPN was partially dissolved in the solvent that caused insufficient reaction performance. Especially, the effect of solvent concentration was much significant under lower reaction temperature condition.

The comparison of 1-methylimidazole and conventional solvents for the yield of MXDA in the hydrogenation is illustrated in Table 1 (entry 3, 14-16). It was observed that the yield of MXDA over 1-methylimidazole as a reaction
Table 2. Solubility of IPN in various organic solvents

\begin{tabular}{ccc}
\hline Solvent & $\begin{array}{c}\text { Temperature } \\
\left({ }^{\circ} \mathrm{C}\right)\end{array}$ & $\begin{array}{c}\text { Solubility } \\
(\mathrm{g}-I P N / g-S o l v e n t)\end{array}$ \\
\hline 1-Methylimidazole & 40 & 0.17 \\
Benzyl Ether & 60 & 0.31 \\
& 40 & 0.04 \\
Mesitylene & 60 & 0.08 \\
& 40 & 0.04 \\
Isopropanol & 60 & 0.07 \\
& 40 & 0.01 \\
& 60 & 0.02 \\
\hline
\end{tabular}

solvent is much higher than the others under identical conditions. This may be attributed to its higher solubility of IPN. The reaction performance was strongly related with the solubility of solvent used. The solubility of 1-methylimiazole is much higher than the others as shown in Table 2. Furthermore, 1-methylimidazole is advantageous in that, as aprotic solvent, it is slightly basic with $p \mathrm{Ka}$ of 7.3-7.8, have a high melting point and do not participate in the hydrogenation.

For the entire reaction conditions, the $100 \%$ of IPN conversion was achieved. However, the duration to complete the reaction strongly depended on the reaction conditions as illustrated in Table 1.

In conclusion, 1-methylimidazole was shown to outperform the other organic solvents in this reaction. Moreover, amount of ammonia with using 1-methylimidazole as a solvent was lower than other processes. Thus, 1-methylimidazole is an attractive solvent in IPN hydrogenation for the production of MXDA.

Acknowledgement. This study was supported by Ministry of Commerce, Industry and Energy of Korea (under Grand No. 2M16450).

\section{References}

1. Kanamori, Y.; Ebata, S.; Tsukahara, K.; Hiramatsu, Y. U.S. Patent 0177735 A1, 2002.

2. Haldar, P.; Mahajani, V. V. Chem. Eng. J. 2004, 104, 27.

3. (a) Nakamura, K.; Otsuka, S.; Kosuge, F.; Shitara, T.; Amakawa, K. U.S. Patent 6476269 B2, 2002. (b) Otsuka, S.; Shitara, T.; Kosuge, F.; Amakawa, K. U.S. Patent 6509490 B2, 2003. (c) Kurek, P. R. U.S. Patent 4482741, 1984.

4. Takamizawa, S.; Wakasa, N.; Fuchikami, T. Synlett 2001, 10, 1623.

5. (a) Vasnin, S.; Geanangel, R. A. Inorg. Chim. Acta 1989, 160, 167. (b) Shapiro, G.; Gomezlor, B. J. Org. Chem. 1994, 59, 5524. (c) Raczynska, E. D. Pol. J. Chem. 1996, 70, 795.

6. General procedure for hydrogenation reaction: In a $100 \mathrm{~mL}$ stainless steel batch reactor, isophthalonitrile $(0.03 \mathrm{~mol}), 1$ methylimidazole $(0.5 \mathrm{~mol})$ and a commercial Ni based catalyst (3 g) were added to the reactor. The reactor was then heated to the reaction temperature with stirring for $30 \mathrm{~min}$ to dissolve IPN completely. After then, ammonia was added to the reactor. When the reactor reached the set temperature, hydrogen was introduced in the reactor to the required set pressure. The products were collected and then analyzed using a gas chromatograph. 